\title{
The Effect of an Adapted Physical Activity Intervention Program on Pre-Service Physical Education Teachers' Self-Efficacy towards Inclusion in Saudi Arabia
}

\author{
Majed M. Alhumaid ${ }^{1,2, *}$, Selina Khoo ${ }^{2} \mathbb{D}$ and Tânia Bastos ${ }^{3}$ \\ 1 Department of Physical Education, College of Education, King Faisal University, Al-Ahsa 31982, Saudi Arabia \\ 2 Centre for Sport and Exercise Sciences, University of Malaya, Kuala Lumpur 50603, Malaysia; \\ selina@um.edu.my \\ 3 Centre of Research, Education, Innovation, and Intervention in Sport, Faculty of Sport, University of Porto, \\ 4200-450 Porto, Portugal; tbastos@fade.up.pt \\ * Correspondence: malhumaid@kfu.edu.sa
}

Citation: Alhumaid, M.M.; Khoo, S.; Bastos, T. The Effect of an Adapted Physical Activity Intervention Program on Pre-Service Physical Education Teachers' Self-Efficacy towards Inclusion in Saudi Arabia. Sustainability 2021, 13, 3459. https:// doi.org/10.3390/su13063459

Academic Editors: Damián Iglesias Gallego, Juan Pedro Fuentes García and José Alberto Frade Martins Parraca

Received: 16 February 2021

Accepted: 19 March 2021

Published: 20 March 2021

Publisher's Note: MDPI stays neutral with regard to jurisdictional claims in published maps and institutional affiliations.

Copyright: (c) 2021 by the authors. Licensee MDPI, Basel, Switzerland. This article is an open access article distributed under the terms and conditions of the Creative Commons Attribution (CC BY) license (https:// creativecommons.org/licenses/by/ $4.0 /)$.

\begin{abstract}
Self-efficacy of pre-service physical education (PE) teachers is an effective predictor of successful inclusion of students with disabilities. However, physical disability is one of the most challenging disabilities to include in PE settings. This study aimed to examine the effectiveness of a 6-week intervention program on the self-efficacy of Saudi pre-service PE teachers towards including students with physical disabilities in general PE classes. Two groups of pre-service PE teachers (35 each in the experimental and control groups; mean age: $22.69 \pm 1.17$ years) enrolled in two universities in Saudi Arabia were recruited into this study. Self-efficacy was measured before and after the intervention program using the Arabic version of the Self-Efficacy Scale for Physical Education Teacher Education Majors toward Children with Disabilities (SE-PETE-D). One-way analysis of covariance (ANCOVA) revealed that a significant improvement in self-efficacy was demonstrated for the experimental group after participation in the intervention program compared to the control group ( $p<0.001, \eta p^{2}=0.53$, large). The results support the systematic implementation of this type of intervention program as an integral part of physical education teacher education programs.
\end{abstract}

Keywords: physical disability; inclusive physical education; students with disabilities; pre-service teacher; adapted physical education

\section{Introduction}

The United Nations Sustainable Development Goal 4 (SDG 4) is intended to provide all students with high-quality inclusive and equitable education [1]. In recent decades, numerous nations supported inclusive education for students with disabilities through government acts and policy frameworks to ensure that inclusive education is provided in all schools throughout their respective education systems [2,3]. Inclusive education refers to the inclusion of students with disabilities in regular schools (instead of being assigned to special schools) [4] with a less restrictive environment [5]. All students are provided with the necessary services and support required [6]. A recent review stated that inclusive education is focused on ensuring equity in education, enhancing engagement, and increasing high-quality learning opportunities for those with and without disabilities [7].

Globally, the past 20 years have seen increasingly rapid advances in the field of inclusion [8]. Consequently, the number of students with disabilities in general education has increased [9]. For instance, in Spain, approximately 140,000 students with disabilities (1.73\% of the total population) have now been included in general schools [10], and in Portugal, $98 \%$ of students with disabilities attended general schools [11]. However, it remains a challenge to successfully incorporate inclusive education to enhance student outcomes and improve teachers' self-efficacy while teaching inclusive classes [12]. 
Based on Article 30 of the International Convention on Rights for Persons with Disabilities, students with disabilities have the right to be included in general physical education (PE), play activities, recreation, and sport [13]. Inclusive PE is defined as the inclusion of students with disabilities in general PE classes by providing them with the necessary services and support [14,15]. Inclusion in PE has generated a considerable and ever-growing body of research on how to implement this inclusion effectively and successfully [16]. Advances in the field of inclusive PE appear likely to improve the participation and learning practices for all students regardless of their individual characteristics [17]. In line with this, UNESCO released a statement acknowledging that students with disabilities must be given the opportunity to participate in adapted, inclusive, and safe PE settings [18]. As a result, many countries have begun to include students with disabilities in general PE classes, including Ireland [19], South Korea [20], Germany [21], Greece [22], and Saudi Arabia [23]. However, despite the increased numbers of students with disabilities in general PE classes, $\mathrm{PE}$ teachers continue to express concerns about their ability to teach and include students with disabilities safely and successfully in their general PE classes [24-26].

The challenges and barriers PE teachers face when teaching students with disabilities in general PE classes have been explored in numerous studies (e.g., [24,27,28]). Most of these studies have reported similar challenges and barriers, including lack of professional preparation, experience, knowledge, and competence; negative attitudes; and low levels of self-efficacy [18,27-32]. Teachers' level of self-efficacy is one of the most important elements for ensuring successful inclusion for students with disabilities in general PE classes [33-36]. According to Block et al. [37], teachers with higher levels of self-efficacy were more likely to implement inclusion strategies (i.e., making accommodations or adaptations for students with disabilities) compared to teachers with lower levels of self-efficacy. PE teachers' levels of self-efficacy can be increased during pre-service PE teacher education (PETE) programs [38]. Therefore, researchers have suggested that better quality training on inclusive practices is crucial for preparing and supporting pre-service PE teachers to confidently teach students with disabilities in general PE classes [2,39-42].

The important role that pre-service teachers' level of self-efficacy plays in including students with disabilities in general PE classes has generated a large amount of research on how pre-service PE teachers' levels of self-efficacy towards inclusion can be positively influenced. For example, some researchers, e.g., the authors of $[43,44]$, assert that academic preparation is one of the most influential factors related to the self-efficacy of pre-service PE teachers towards teaching students with disabilities. However, upon further investigation, Taliaferro et al. [36] indicated that despite significant increases in pre-service PE teachers' self-efficacy beliefs during the semester, no significant differences were evident among participants who had completed a 16-week adapted physical education (APE) course and those who had not.

Few studies have investigated the effectiveness of a short-term intervention program. One example is Layne and Blasingame's [45] study which investigated the efficacy of a short-term intervention designed to provide pre-service PE teachers who attended a PETE program with practical one-to-one experience of teaching students with profound and severe disabilities over a 5-week period. The results indicated that the pre-service $\mathrm{PE}$ teachers reported having insufficient experience of teaching this cohort beforehand. However, the results show that participants reported gaining valuable experience via their one-on-one instruction and a greater appreciation for teaching students with disabilities. More recently, Foley et al. [39] examined the effects of a 1-week intensive sports camp for students with visual impairments on pre-service PE teachers' self-efficacy toward teaching students with intellectual disabilities, physical disabilities, and visual impairments in PE settings. The findings indicated that the participants' self-efficacy scores toward teaching students with these three types of disabilities significantly increased after completing the program. This finding is in line with Neville et al.'s [38] study, which found that pre-service PE teachers' levels of self-efficacy increased after they participated in a 1-day inclusive PE program (6 h; theoretical and practical). In summary, these studies suggest that 
providing more practical opportunities for pre-service PE teachers to work with students with disabilities can play a critical and valuable part in successful inclusive PETE programs.

Practical intervention programs are often provided as a means of improving preservice teachers' professional skills [46]. The literature shows that intervention programs based on social cognitive theory positively impact teachers' levels of self-efficacy [47] and professionalism in the workplace [48]. Intervention programs designed specifically to improve pre-service PE teachers' self-efficacy and skills represent an important way of addressing the weaknesses in current PETE programs for pre-service PE teachers who wish to teach general PE classes for students with disabilities [3,36,44,49]. Most of the research has been conducted in educational settings in Western countries. Limited research has examined the effectiveness of intervention programs to enhance pre-service PE teachers' self-efficacy towards including students with disabilities in general PE settings in nonWestern societies. More specifically, no studies have examined the impact of an adapted physical activity (APA) program on the self-efficacy of Saudi Arabian pre-service PE teachers towards teaching students with disabilities in PE settings.

Although pre-service teachers' levels of self-efficacy are a significant predictor of successful inclusion $[35,50]$, there is a lack of research on inclusion in PE in the Saudi Arabian context as well as in Arab countries more broadly [51]. For example, a recent study by Alhumaid et al. [52] concluded that Saudi pre-service PE teachers reported the lowest levels of self-efficacy towards including students with physical disabilities compared to other types of disabilities (i.e., intellectual disabilities and visual impairments). In view of the above considerations, the aim of the present study was to investigate the effect of a 6-week APA intervention program in improving the self-efficacy levels of pre-service Saudi Arabian PE teachers toward including students with physical disabilities in general PE classes. Specifically, we aimed to explore the differences in self-efficacy scores between the research groups (experimental and control) according to different independent variables (e.g., having experience in teaching students with disabilities, taking the APE course).

\section{Materials and Methods}

\subsection{Participants}

The participants were 70 (experimental group $n=35$, control group $n=35$ ) male preservice PE teachers aged between 21 and 26 years old $(M=22.69, S D=1.17)$ and enrolled in the fourth year of a PETE program in two universities in Saudi Arabia. This cohort was chosen because the participants were close to graduating and would be taking up teaching positions the following year. Only male pre-service PE teachers were included in the study because there were no PETE programs for female students in Saudi Arabia at the time of data collection. The majority of the participants $(91.4 \%)$ reported that they do not have a family member with a disability; however, a small percentage $(14.3 \%)$ of the participants reported having a friend with a disability. The majority of the participants $(95.7 \%)$ had taken the APE course; however, a small percentage (4.3\%) of participants reported having previous experience of teaching PE to students with disabilities. Overall, $17.1 \%$ of the participants reported having observed a PE teacher teaching students with disabilities.

\subsection{Intervention}

The primary purpose of this APA intervention program was to improve pre-service PE teachers' level of self-efficacy in teaching students with physical disabilities in general PE classes. Each session of the program was prepared and designed based on a comprehensive review of the literature on APA programs to target one or more of the four sources of selfefficacy (mastery experience, vicarious experience, verbal persuasion, and physiological states) [53]. Bandura's self-efficacy theory [53] suggests that these four sources can impact and develop the level of self-efficacy.

First, mastery experience is an individual's previous experience in implementing a particular task successfully [34]. Mastery experience in the present study was obtained when participants experienced different tasks, such as creating a safe environment, mod- 
ifying equipment and activities, practicing simulations, teaching their peers both with and without simulated disabilities, working in adapted sports programs, and playing para-sports with para-athletes [36]. Second, vicarious experience, or the observation of individuals who have achieved successful efforts in doing a specific job, makes observers feel that they can achieve the same outcomes [54]. In the present study, vicarious experience was achieved when participants observed PE teachers teaching students with physical disabilities in general PE classes. Third, verbal persuasion refers to individuals receiving support, encouragement, and positive feedback from others, such as peers, colleagues, and instructors [34]. Participants in the present study were provided with verbal (i.e., social) persuasion when they attended the theoretical lecture which was held at the first session and provided by a group of specialists. Verbal persuasion may also come into effect when participants receive support, encouragement, and motivation from teachers, peers, and instructors after each task in the program $[34,55]$. Finally, physiological states refer to individuals' feelings or reactions when they face challenges [56]. Participants in the present study were likely to experience a range of physiological states when discussing their feelings and feedback at the end of each session of the program. This may also occur when they engage in more practical teaching experiences [45].

\subsubsection{The Incluye-T Guide}

A review by Hutzler et al. [12] concluded that the acquisition of substantial and structured quality practicum experience with students with various disabilities (including physical disability) is likely to be very important for establishing pre-service PE teachers self-efficacy towards inclusion. Hence, to make the current APA intervention program more effective and valuable, the Incluye-T guide [57] was utilized as the intervention program's main reference. The Incluye-T guide (translated from the original version in Spanish into English by Reina et al. [58]) was created with a specific focus on inclusion in PE of students with different types of disabilities, including intellectual disabilities, physical disabilities, visual impairments, and hearing impairments [58].

The Incluye-T guide suggests that before starting a practical session, it is essential to raise awareness of disabilities to encourage more understanding and empathy for people with different disabilities. The participants should be familiar with the characteristics and disabilities of the students they are going to work with. They also need to know the appropriate materials to facilitate the proposed activities for the learners they are teaching. The Incluye-T guide also suggests that participants should be able to perform a simulation of the disability and explain why it is significant. Moreover, the participants should perform the necessary adaptations and modifications for each activity (e.g., material, time, rules, and space). Finally, at the end of the session, the Incluye-T guide also suggests that participants should discuss their feelings and provide feedback on any issues that arose during the session.

\subsubsection{Validity of the Intervention Program}

To ensure the intervention program's content validity, it was reviewed by a panel of three experts in APA and APE from various countries: (i) a professor from Saudi Arabia with extensive research and teaching experience in APE and (ii) two professors from Europe with extensive experience in research and teaching in APE and APA. The panel experts were asked to provide feedback on content validity from different social perspectives.

Specifically, the experts were asked to critique and provide suggestions on the content and duration of the intervention program. The feedback and responses indicated that the experts felt the intervention program would successfully impact the participants' selfefficacy levels. They also commented that the intervention program would be valuable as it was prepared and designed based on a comprehensive review of the literature on APA programs. However, the experts suggested the addition of several elements that may have a positive impact on the intervention program's effectiveness. For instance, one expert suggested that it is crucial to provide an element of controlled mastery experience, which 
could be either during participants' microteaching (i.e., when teaching their peers with simulated disabilities) and/or students with disabilities in a relatively sterile environment (e.g., within an after-school physical activity program). With this feedback in mind, we made modifications to the intervention program. However, none of these modifications changed the overall aims of the intervention program.

The APA intervention program consisted of six sessions of 3 hours per session. The intervention was conducted once a week for 6 weeks (for a total of $18 \mathrm{~h}$ ). The 18-h duration (6 sessions; $3 \mathrm{~h}$ each session) was considered effective in improving the self-efficacy levels as suggested by a previous study, i.e., [10]. The APA intervention program was conducted on-campus (e.g., a conference room, a gymnasium) and off-campus (e.g., a neighborhood club, an inclusive public school, a Paralympic sport club gymnasium) (see Table 1). Details of the intervention are shown in Table 1.

Table 1. Content of the adapted physical activity (APA) intervention program.

\begin{tabular}{ccl}
\hline Week & $\begin{array}{c}\text { Targeted Source, } \\
\text { Duration, Place }\end{array}$ & Description \\
\hline $\begin{array}{c}\text { Theoretical } \\
\text { week }\end{array}$ & $\begin{array}{c}\text { Verbal persuasion, } 3 \mathrm{~h}, \\
\text { on-campus }\end{array}$ & $\begin{array}{l}\text { Lecture titled "Toward Successful Inclusive Physical Education" given by an APE professor, } \\
\text { SE professor, PE teachers, and the first author }\end{array}$ \\
\hline $\begin{array}{c}\text { Observation } \\
\text { week }\end{array}$ & $\begin{array}{c}\text { Vicarious experience and } \\
\text { physiological states, } 3 \mathrm{~h}, \\
\text { inclusive school }\end{array}$ & $\begin{array}{l}\text { Participants observed in-service PE teachers teaching students with physical disabilities and } \\
\text { students without disabilities in general PE classes } \\
\text { At the end of the session, participants discussed their feelings when observing the PE } \\
\text { teachers teaching students with disabilities and provided feedback on this task to the first } \\
\text { author (e.g., how this observation changed their preparation to do the same task with their } \\
\text { students with physical disabilities) }\end{array}$
\end{tabular}

- Participants did the following:

1. Practice simulation (using the Incluye-T guide)

2. Practice making a safe environment (e.g., avoid very cold temperatures which increase hypertonia), modifying equipment (e.g., decrease the height of the basketball hoops and the volleyball net), modifying activities (e.g., modify Zig-Zag relays activity using wheelchairs), and games (e.g., reduce the number of players to enhance freedom of movement and ensure more active participation) for students with physical disabilities (using the Incluye-T guide)

$3 \quad$ Mastery experience and

Practical week physiological states, $3 \mathrm{~h}$, on-campus
At the end of the session, participants discussed their feelings when simulating the physical disability and practicing different tasks and provided feedback on these tasks to the first author (e.g., participants discussed how simulation experiences changed their confidence in dealing with students with physical disabilities) $\begin{array}{ll}4 & \text { Mastery experience and } \\ \text { physiological states, } 3 \mathrm{~h} \text {, }\end{array}$

Practical week on-campus

\section{Participants did the following:}

1. Teach their peers with simulated disabilities and without disabilities

- $\quad$ At the end of the session, participants discussed their feelings when teaching their peers with simulated disabilities and provided feedback on this task to the first author (e.g., participants discussed the challenges they faced when teaching their peers with simulated disabilities)

\begin{tabular}{|c|c|c|c|}
\hline \multirow{3}{*}{$\begin{array}{l}5 \\
\text { Adapted sport } \\
\text { week }\end{array}$} & \multirow{3}{*}{$\begin{array}{l}\text { Mastery experience and } \\
\text { physiological states, } 3 \mathrm{~h} \text {, } \\
\text { off-campus }\end{array}$} & - & $\begin{array}{l}\text { The participants had the opportunity to work in an adapted sports program that was held at } \\
\text { a neighborhood club which was organized and supervised by experienced in-service PE } \\
\text { teachers } \\
\text { Participants did the following: }\end{array}$ \\
\hline & & & $\begin{array}{l}\text { 1. Practice observing PE teachers preparing adapted sports } \\
\text { 2. Practice making activities and games for students with and without disabilities }\end{array}$ \\
\hline & & - & $\begin{array}{l}\text { At the end of the session, participants discussed their feelings when working in the adapted } \\
\text { sports program and provided feedback on this task to the first author (e.g., whether or not } \\
\text { participants felt comfortable doing this activity for students with disabilities) }\end{array}$ \\
\hline
\end{tabular}

\section{6 \\ Para-sport week}

Mastery experience, $3 \mathrm{~h}$, Paralympic sport club
The participants had the opportunity to play para-sports with para-athletes (wheelchair basketball and sitting volleyball)

The participants had the opportunity to watch para-athletes playing sports 


\subsection{Measures}

\subsubsection{Demographic Form}

The demographic form covered the following information: (i) participant's age, (ii) academic year, (iii) previous contact with a person with a disability (i.e., a family member or a friend), (iv) experience teaching students with disabilities, (v) previous participation in an APE course, (vi) previous observation of a PE class involving students with disabilities, and (vii) experience of having been persuaded to teach a PE class for students with disabilities.

2.3.2. Self-Efficacy Scale for Physical Education Teacher Education Majors toward Children with Disabilities (SE-PETE-D)

The Arabic version of the Self-Efficacy Scale for Physical Education Teacher Education Majors toward Children with Disabilities (SE-PETE-D) [37] was utilized to examine participants' level of self-efficacy towards including students with physical disabilities in general PE classes. This questionnaire was translated and validated from the original English version to Arabic by Hutzler and Daniel-Shama [33]. This questionnaire explores PE teachers' perceptions of self-efficacy towards the inclusion of students with intellectual disabilities, physical disabilities, and visual impairments. However, because of the purpose of the present study, only the section relevant to physical disability was applied.

The SE-PETE-D for physical disability consists of 12 questions. The section begins with a description of a student with a physical disability, and participants were asked to rate their confidence in their ability to implement tasks, such as modifying instructions for the student, modifying equipment, creating a safe environment, and instructing peers. Examples of questions are as follows: "How confident are you in directing Fahad's peers to help him during the fitness test?" and "How confident are you in your ability to create individual goals for Fahad during the fitness test?" Participants were asked to rank their responses on a 5-point Likert scale ranging from 1 (no confidence) to 5 (complete confidence). A higher score indicates a higher perception of self-efficacy to include students with physical disabilities in general PE classes [8]. To improve the relevance of the questionnaire to the Saudi Arabian setting and better fit the cohort, slight changes were made, such as using common Saudi names (e.g., from Ashton to Fahad), using the term "middle school" instead of "high school", and using "third year" instead of "ninth grade".

The Arabic version of the SE-PETE-D for physical disability demonstrated good internal reliability with a Cronbach's alpha of 0.97 for the physical disability subscale [33]. The Kaiser-Meyer-Olkin (KMO) index for the SE-PETE-D for the physical disability subscale was 0.956 . Moreover, Bartlett's test of sphericity chi-squared was statistically significant in the SE-PETE-D for the physical disability subscale.

\subsection{Procedure}

Research ethics approval from the University of Malaya Research Ethics Committee (UM. TNC2/UMREC - 452) and permission from the Ministry of Education in Saudi Arabia were obtained. We then invited fourth-year pre-service PE teachers in two Saudi universities to participate in this study. We divided the participants in this study nonrandomly into two groups. The experimental group was from one university in the Eastern Region of Saudi Arabia, and the control group was from another university in the Western Region of Saudi Arabia. This approach was applied in order to avoid data contamination and direct or indirect communication between the experimental and control groups during the intervention program. Those who agreed to participate after reading the information sheet were given the consent form to sign. The experimental group participated in the 6-week APA intervention program. Participants from both groups completed the SE-PETE-D for physical disability questionnaire at baseline. Participants in the experimental group then participated in the 6-week APA intervention program and completed the SE-PETE-D for physical disability again after the intervention. Participants in the control group did not receive the intervention program and completed the SE-PETE-D for physical disability again after 6 weeks. Participants could withdraw from the study at any time. 


\subsection{Data Analysis}

Mean $(M)$ and standard deviation $(S D)$ were computed for the overall SE-PETE-D for physical disability. The reliability of SE-PETE-D for physical disability was examined using Cronbach's alpha calculation, considering scores over 0.70 acceptable [59]. An independent sample t-test and Mann-Whitney $U$ test were used to explore the differences in self-efficacy scores between the research groups (experimental and control). After checking that the assumptions were met, an analysis of covariance (ANCOVA) test was used in order to determine the differences between the self-efficacy post-test scores and the impact of coexistence factors (independent variables) and covariate factors (self-efficacy pre-test scores). The one-way ANCOVA is an appropriate statistical test to determine the difference in and effects of covariate and fixed factors on the overall self-efficacy scores toward teaching students with physical disability in the post-test [60]. Partial eta-squared $\left(\eta p^{2}\right)$ was used to calculate the practical significance as a measure of effect size for mean differences with the following interpretation: $<0.02$, between 0.02 and 0.026 , and $>0.26$ were considered small, moderate, and large, respectively [61]. The Statistical Package for the Social Sciences (SPSS) software version 22.00 (SPSS Inc., Chicago, IL, USA) was utilized to run all statistical analyses. The significance level was set at $p<0.05$.

\section{Results}

\subsection{Scale Reliability and Internal Consistency}

The results indicated good internal consistency for the SE-PETE-D for physical disability with a Cronbach's alpha of 0.89 for pre-test and 0.93 for post-test [62]. The KaiserMeyer-Olkin (KMO) index was 0.75 for the pre-test SE-PETE-D for physical disability and 0.88 for the post-test.

\subsection{Differences in the Self-Efficacy Scores between Experimental and Control Groups}

An independent-samples t-test indicated a significant difference between the postintervention self-efficacy scores for the experimental and control groups $(p<0.001)$, whereas the pre-intervention self-efficacy scores did not reveal any significant differences between the two groups. Based on the results for the nonparametric test (Mann-Whitney U test), Table 2 shows no significant differences between the two groups based on taking the APE course both for pre-intervention and post-intervention, and this was also the case for having previous experience of teaching students with disabilities. Moreover, the other variables did not reveal any significant differences between the two groups (see Table 2).

Table 2. Exploring the differences in self-efficacy scores between the research groups and other characteristics.

\begin{tabular}{|c|c|c|c|c|c|c|c|c|c|c|}
\hline \multirow{2}{*}{ Independent Variables } & & \multicolumn{5}{|c|}{ Pre-Intervention } & \multicolumn{4}{|c|}{ Post-Intervention } \\
\hline & & $n$ & $\mathbf{M} \pm \mathrm{SD}$ & $M_{\text {diff }}$ & $t / z$ & $p$ & $\mathbf{M} \pm \mathbf{S D}$ & $M_{\text {diff }}$ & $t / z$ & $p$ \\
\hline Groups & $\begin{array}{l}\mathrm{EG} \\
\mathrm{CG}\end{array}$ & $\begin{array}{l}35 \\
35\end{array}$ & $\begin{array}{l}37.14 \pm 6.09 \\
33.29 \pm 9.70\end{array}$ & 3.86 & $1.993^{\mathrm{a}}$ & 0.051 & $\begin{array}{l}47.34 \pm 5.08 \\
33.86 \pm 8.61\end{array}$ & 13.49 & $7.983^{a}$ & $<0.001$ \\
\hline $\begin{array}{l}\text { Having a family member with a } \\
\text { disability }\end{array}$ & $\begin{array}{l}\text { No } \\
\text { Yes }\end{array}$ & $\begin{array}{l}64 \\
6\end{array}$ & $\begin{array}{l}35.06 \pm 8.41 \\
36.83 \pm 7.03\end{array}$ & -1.77 & $0.462^{b}$ & 0.660 & $\begin{array}{l}40.25 \pm 9.92 \\
44.33 \pm 7.55\end{array}$ & -4.08 & $0.84^{b}$ & 0.417 \\
\hline Having a friend with a disability & $\begin{array}{l}\text { No } \\
\text { Yes }\end{array}$ & $\begin{array}{l}60 \\
10\end{array}$ & $\begin{array}{l}34.90 \pm 8.53 \\
37.10 \pm 6.52\end{array}$ & -2.20 & $0.832^{b}$ & 0.440 & $\begin{array}{c}39.87 \pm 9.48 \\
45.00 \pm 10.80\end{array}$ & -5.13 & $1.891^{\mathrm{b}}$ & 0.056 \\
\hline $\begin{array}{l}\text { Having experience teaching } \\
\text { students with disabilities }\end{array}$ & $\begin{array}{l}\text { No } \\
\text { Yes }\end{array}$ & $\begin{array}{c}67 \\
3\end{array}$ & $\begin{array}{l}34.87 \pm 8.26 \\
43.00 \pm 4.00\end{array}$ & -8.13 & $1.772^{b}$ & 0.078 & $\begin{array}{l}40.27 \pm 9.81 \\
48.00 \pm 5.20\end{array}$ & -7.73 & $1.219^{b}$ & 0.236 \\
\hline Taken APE course & $\begin{array}{l}\text { No } \\
\text { Yes }\end{array}$ & $\begin{array}{l}3 \\
67\end{array}$ & $\begin{array}{l}37.33 \pm 6.66 \\
35.12 \pm 8.36\end{array}$ & 2.21 & $0.632^{b}$ & 0.660 & $\begin{array}{l}42.67 \pm 9.45 \\
40.51 \pm 9.84\end{array}$ & 2.16 & $-0.305^{b}$ & 0.785 \\
\hline $\begin{array}{l}\text { Observed a PE teacher teaching } \\
\text { students with disabilities }\end{array}$ & $\begin{array}{l}\text { No } \\
\text { Yes }\end{array}$ & $\begin{array}{l}58 \\
12\end{array}$ & $\begin{array}{l}34.47 \pm 8.67 \\
38.83 \pm 4.73\end{array}$ & -4.37 & $1.67^{b}$ & 0.095 & $\begin{array}{c}39.97 \pm 10.12 \\
43.67 \pm 7.14\end{array}$ & -3.70 & $1.076^{\mathrm{b}}$ & 0.282 \\
\hline $\begin{array}{l}\text { Have been persuaded to teach } \\
\text { PE to students with disabilities }\end{array}$ & $\begin{array}{l}\text { No } \\
\text { Yes }\end{array}$ & $\begin{array}{l}60 \\
10\end{array}$ & $\begin{array}{l}34.78 \pm 8.56 \\
37.80 \pm 5.80\end{array}$ & -3.02 & $1.093^{b}$ & 0.274 & $\begin{array}{l}40.15 \pm 10.07 \\
43.30 \pm 7.51\end{array}$ & -3.15 & $0.739^{b}$ & 0.460 \\
\hline
\end{tabular}

${ }^{\mathrm{a}}$ : Independent $t$-test. ${ }^{\mathrm{b}}$ : Mann-Whitney U test; EG: experimental group, CG: control group, APE: adapted physical education, M: mean, SD: standard deviation. 


\subsection{Self-Efficacy for Teaching Students with Physical Disabilities}

Based on the ANCOVA results, it is noteworthy that the pre-test self-efficacy scores and the groups to which the participants belonged (experimental or control) were the only significant predictors of self-efficacy in this model.

The post-test self-efficacy scores showed a higher impact on self-efficacy between the groups than the pre-test scores. As shown in Table 3, the one-way ANCOVA results revealed a positive and significant main effect on self-efficacy in the post-test for both the experimental and control groups $\left(\mathrm{F}(1.67)=76.159 ; p<0.001 ; \eta p^{2}=0.53\right.$, large) (see also Figure 1). In other words, the post-test self-efficacy scores were strongly affected by the intervention program when compared to the pre-test scores.

Table 3. Test of between-subjects effects.

\begin{tabular}{ccccccc}
\hline \multicolumn{7}{c}{ Predictors of Self-Efficacy at Post-Test } \\
\hline Source & Type III SS & df & MS & F & $p$ & $\eta \boldsymbol{p}^{\mathbf{2}}$ \\
\hline Corrected Model & 4755.854 & 2 & 2377.927 & 87.398 & $<0.001$ & 0.72 \\
Intercept & 1325.315 & 1 & 1325.315 & 48.710 & $<0.001$ & 0.42 \\
Self-efficacy Pre-test & 1573.226 & 1 & 1573.226 & 57.822 & $<0.001$ & 0.46 \\
Group & 2072.156 & 1 & 2072.156 & 76.159 & $<0.001$ & 0.53 \\
Error & 1822.946 & 67 & 27.208 & & & \\
\hline
\end{tabular}

R-squared: 0.723 (adjusted R-squared: 0.715). SS: sum of squares, df: degrees of freedom, MS: mean square, F: F-ratio.

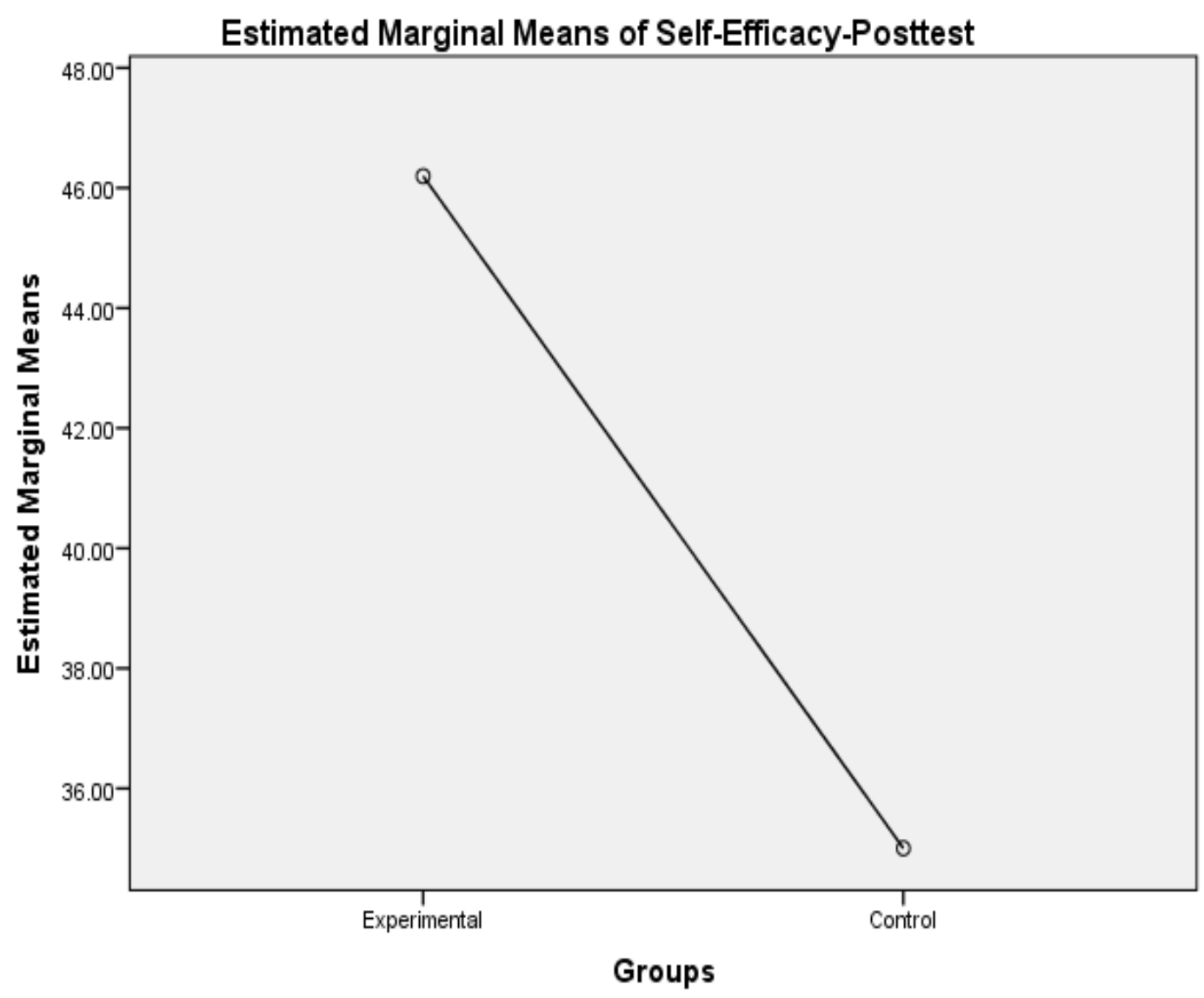

Covariates appearing in the model are evaluated at the following values: Self-Efficacy-Pretest $=35.2143$

Figure 1. Difference in self-efficacy score at post-test between experimental and control groups.

Figure 1 shows the differences in the scores between the experimental and control groups at post-test for participants' self-efficacy towards including students with physical 
disabilities. As shown in Figure 1, the experimental group presented a higher level of self-efficacy towards including students with physical disabilities in general PE classes after participation in the intervention program when compared to the control group's self-efficacy scores.

\section{Discussion}

The present study aimed to examine the effectiveness of a 6-week intervention program on the self-efficacy of Saudi pre-service PE teachers toward teaching students with physical disabilities in general PE classes.

Based on the findings, significant improvements in self-efficacy levels toward teaching students with physical disabilities in general PE settings were found among the experimental group following the 6-week intervention program compared to the control group. In line with this finding, previous studies have also demonstrated that significant positive changes in participants' self-efficacy towards the inclusion of students with disabilities in general PE settings were found after they had participated in 1-day [38], 1-week [39], 3-week [8,10], 5-week [45], and 10-week intervention programs [44]. However, the present study's results are inconsistent with other previous studies that suggest nonsignificant improvements in participants' self-efficacy and attitudes toward inclusion were evident after a 1-day workshop [46] and a 2-day workshop [63]. These inconsistent findings may be explained in two ways.

One possible explanation for why the present study's findings were inconsistent with Taliaferro and Harris [46] and Haegele et al.'s [63] findings might be because of the short duration of these interventions (1 and 2 days). Specifically, the 1-day and 2-day interventions and workshops may have been too short to have been effective in improving the participants' level of self-efficacy. For example, Reina et al.'s [10] intervention involved in-service PE teachers undergoing 18 face-to-face hours of instruction on inclusive teaching practices, and this long duration is likely to have significantly improved the participants' levels of self-efficacy. Similarly, the present study's intervention program also featured 18 face-to-face hours of instruction on including students with physical disabilities in general PE classes. This long duration is also likely to have positively affected the experimental group participants' level of self-efficacy. The literature suggests that the more experience pre-service teachers gain in learning how to teach students with disabilities inclusively, the higher their self-efficacy is likely to be [2,64,65]. For example, Koh [34] concluded that pre-service PE teachers who had completed more than 15 credits on an APE course reported significant improvements in their level of self-efficacy towards including students with disabilities. More recently, Aldabas [66] concluded that teachers with more experience in teaching students with disabilities demonstrated higher confidence toward teaching in inclusive settings than those with less experience. Therefore, the present study's findings reinforce the notion that pre-service PE teachers with better and more comprehensive experience of teaching students with disabilities demonstrate more positive attitudes and higher levels of self-efficacy toward inclusion $[3,36,43]$. In summary, this suggests that longer interventions are significantly more effective.

Another possible explanation for why the present study's findings were inconsistent with previous studies (e.g., [63]) is that the intervention program's content and quality were also important. For example, despite the short duration of Neville et al.'s [38] workshop (6 h over 1 day), the authors indicated that the participants' perceptions about the workshop's quality were a critical predictor of the degree to which their self-efficacy improved. The authors also demonstrated that the success of their workshop was due to the quality of the course tutors' behaviors, workshop design, and overall preparation. In line with this, the present study's intervention program was designed to ensure that it included highly professional tutors and high-quality content. In particular, the present intervention program was delivered and presented by specialist APE university professors and special education and PE teachers with comprehensive experience in teaching students with disabilities. Moreover, the present intervention program's content was prepared and designed based on 
a comprehensive review of the literature on APA intervention programs and suggestions provided by the Incluye-T guide [58]. For example, Haegele et al. [63] concluded that their workshop failed to achieve its aim of enhancing teachers' attitudes toward inclusion because it primarily focused on and emphasized theoretical constructs, such as knowledge of the relevant legislation, disability definitions, and activity modifications. With this in mind, in the present study, we focused on both theoretical and practical aspects of the intervention program. Relatedly, Neville et al.'s [38] workshops also provided theoretical and practical aspects (e.g., modifying inclusive PE activities). Therefore, the practical aspects and the execution quality of such interventions and workshops are essential to successfully prepare PE teachers to teach students with disabilities.

The present study reveals several implications for improving the quality of universitylevel inclusive education in PE. First, as there is a lack of practical data on the inclusion of students with disabilities in general PE classes in Saudi Arabia, the present study's findings would benefit Saudi Arabian educational decision-makers-as well as those in other non-Western countries-by providing insights on improving pre-service PE teachers' self-efficacy towards inclusion. Second, it is crucial to facilitate a better degree of interaction between pre-service PE teachers and students with physical disabilities as well as paraathletes in order to improve pre-service PE teachers' confidence to include students with disabilities in their general PE classes [8]. This could be achieved through providing more practical programs, which aim to increase interaction between students with disabilities and pre-service PE teachers to enhance the level of self-efficacy of the latter towards inclusive teaching. Third, the findings also suggest the importance of providing a supportive, inclusivity-focused learning environment for pre-service PE teachers within their school [2]. Finally, in light of our findings, we argue that promoting sustainability in education requires pre-service PE teachers to acquire higher self-efficacy levels toward the inclusion of students with disabilities to ensure positive teaching and learning outcomes [52].

Despite the strengths of this study, certain limitations merit discussion. First, only male participants were recruited in this study. While it would have been useful to sample female participants, the present study was limited to male participants; this is because no PETE programs existed for females in Saudi Arabia at the time of data collection. Therefore, this limitation provides an interesting avenue for future research. Second, the present study did not adopt a randomized experimental research design; this means the results may be subject to sampling bias and may not be completely generalizable to other educational contexts. Third, participation was secured voluntarily, which could have skewed the sample, making it unrepresentative (e.g., by including only highly motivated pre-service PE teachers who were willing to adapt their approach). Therefore, although the results may be generalized to other contexts, care should be taken to ensure that this consideration is taken into account. Fourth, although a previous study demonstrated that such programs were successful in improving participants' self-efficacy towards including students with intellectual disabilities, physical disabilities, and visual impairments [10], the present study focused on the inclusion of students with physical disabilities. However, this decision was made based on a previous study that reported that Saudi pre-service PE teachers' selfefficacy was lowest towards the inclusion of students with physical disabilities compared to intellectual disabilities and visual impairments [52]. Finally, the intervention program environment was highly structured and supportive; therefore, these factors might have artificially affected the participants' level of self-efficacy.

\section{Conclusions}

The present study underlines the requirement for implementing effective interventions for pre-service PE teachers on a PETE course to enhance their self-efficacy towards teaching students with physical disabilities in inclusive settings. The findings indicated that no significant differences were found between the groups based on the independent variables (e.g., having experience in teaching students with disabilities, taking the APE course). Moreover, the 6-week intervention program in this study had a statistically significant effect 
in raising the participants' self-efficacy toward including students with physical disabilities in general PE classes. In particular, significant improvements in the experimental group's levels of self-efficacy in teaching students with physical disabilities in general PE settings were achieved after they completed the 6-week APA intervention program compared to the control group. Therefore, such intervention programs should be widely and continually implemented as integral modules in Saudi Arabian PETE courses and similar educational contexts (e.g., general and special education programs) to achieve inclusive education and provide maximum benefit for students with disabilities. Based on the results, it appears that such interventions should run for a minimum of $18 \mathrm{~h}$ duration in 6 weeks to ensure that pre-service PE teachers gain the full benefit of improved self-efficacy towards teaching students with physical disabilities, which, in turn, will enable these students to maximize their potential in PE. This will also benefit students with disabilities in their personal lives through better self-esteem due to good achievement in sports.

Author Contributions: Conceptualization, M.M.A.; methodology, M.M.A., S.K. and T.B.; validation, M.M.A., S.K. and T.B.; formal analysis, M.M.A.; investigation, S.K. and T.B.; resources, M.M.A., S.K. and T.B.; data curation, M.M.A.; writing—original draft preparation, M.M.A.; writing-review and editing, M.M.A., S.K. and T.B.; visualization, M.M.A., S.K. and T.B.; supervision, S.K. and T.B.; project administration, M.M.A. and S.K.; funding acquisition, M.M.A. All authors have read and agreed to the published version of the manuscript.

Funding: This research was funded by the Deanship of Scientific Research, King Faisal University, grant number 206090.

Institutional Review Board Statement: This study was conducted according to the guidelines of the Declaration of Helsinki, and approved by the Research Ethics Committee of University of Malaya (protocol code UM. TNC2/UMREC—452 approved on 12 February 2019).

Informed Consent Statement: Informed consent was obtained from all subjects involved in the study.

Acknowledgments: The authors acknowledge the Deanship of Scientific Research at King Faisal University for the financial support under Nasher Track (Grant No. 206090).

Conflicts of Interest: The authors declare no conflict of interest.

\section{References}

1. UN SDGs. Transforming Our World: The 2030 Agenda for Sustainable Development. Resolution Adopted by the UN General Assembly. 25 September 2015. Available online: https://sustainabledevelopment.un.org/post2015/transformingourworld (accessed on 20 June 2020).

2. Granell, J.C.; Goig, R.L.; Raga, M.G.; Maher, A. Perceived Competence to Teach Students with Special Educational Needs in Physical Education: The Voice of University Students from Spain and United Kingdom. Retos. Nuevas. Tendencias. Educ. Fis. Deporte. Rec. 2021, 39, 372-378.

3. Wang, Y.-S.; Liu, L.; Wei, X.-W.; Block, M.E. The Self-Efficacy of Preservice Physical Education Teachers in Disabilities Education in China. Sustainability 2020, 12, 7283. [CrossRef]

4. Rafferty, Y.; Boettcher, C.; Griffin, K.W. Benefits and Risks of Reverse Inclusion for Preschoolers with and without Disabilities: Parents' Perspectives. J. Early Interv. 2001, 24, 266-286. [CrossRef]

5. Umhoefer, D.L.; Vargas, T.M.; Beyer, R. Adapted Physical Education Service Approaches and the Effects on the Perceived Efficacy Beliefs of General Physical Education Teachers. Phys. Educ. 2015, 72, 361-381.

6. Haegele, J.A.; Hodge, S. Disability Discourse: Overview and Critiques of the Medical and Social Models. Quest 2016, 68, 193-206. [CrossRef]

7. Schwab, S. Inclusive and Special Education in Europe. In Oxford Research Encyclopedia of Education; Oxford University Press: Oxford, UK, 2020.

8. Reina, R.; Santana, A.; Montesdeoca, R.; Roldan, A. Improving Self-Efficacy Towards Inclusion in In-service Physical Education Teachers: A Comparison between Insular and Peninsular Regions in Spain. Sustainability 2019, 11, 5824. [CrossRef]

9. Kwon, E.H. Status of Introductory APE Course and Infusion in PETE Program. Palaestra 2018, 32, 32-39.

10. Reina, R.; Healy, S.; Roldan, A.; Hemmelmayr, I.; Klavina, A. Incluye-T: A Professional Development Program to Increase the Self-Efficacy of Physical Educators towards Inclusion. Phys. Educ. Sport. Pedagog. 2019, 24, 319-331. [CrossRef]

11. Rodrigues, D.; Nogueira, J. Educação Especial e Inclusiva em Portugal Factos e Opções. Rev. Educ. Incl. 2010, 3, 97-109. 
12. Hutzler, Y.; Meier, S.; Reuker, S.; Zitomer, M. Attitudes and Self-Efficacy of Physical Education Teachers toward Inclusion of Children with Disabilities: A Narrative Review of International Literature. Phys. Educ. Sport. Pedagog. 2019, 24, $249-266$. [CrossRef]

13. UN General Assembly. Convention on the Rights of Persons with Disabilities: Resolution/adopted by the General Assembly. A/RES/61/106. 2007. Available online: https://www.refworld.org/docid/45f973632.html (accessed on 23 June 2020).

14. Bastos, T.; Teixeira, J.; Amaral, M.; Corredeira, R. Physical Education and Sport as a Means to Empower Children with Disability in Educational and Community Settings: The Contribution of Paralympic Education Focusing on Peers' Interactions. In Inclusive Physical Activities: International Perspectives; Alexandre, J., Ed.; Information Age Publishing Inc.: Charlotte, NC, USA, 2017; pp. 91-108.

15. Wilhelmsen, T.; Sørensen, M. Inclusion of Children with Disabilities in Physical Education: A Systematic Review of Literature from 2009 to 2015. Adapt. Phys. Act. Q. 2017, 34, 311-337. [CrossRef]

16. Maher, A.J.; Fitzgerald, H.; McVeigh, J. Factors Influencing the Culture of Special School Physical Education: A Gramscian Critique. Eur. Phys. Educ. Rev. 2020, 26, 954-969. [CrossRef]

17. Tindall, D.; MacDonald, W.; Carroll, E.; Moody, B. Pre-service Teachers' Attitudes towards Children with Disabilities: An Irish Perspective. Eur. Phys. Educ. Rev. 2015, 21, 206-221. [CrossRef]

18. UNESCO. Education for All Global Monitoring Report 2015: Education for All 2000-2015-Achievements and Challenges; UNESCO Publishing: Paris, France, 2015.

19. Meegan, S.; MacPhail, A. Irish Physical Educators' Attitude toward Teaching Students with Special Educational Needs. Eur. Phys. Educ. Rev. 2006, 12, 75-97. [CrossRef]

20. Jeong, M.; Block, M.E. Physical Education Teachers' Beliefs and Intentions Toward Teaching Students with Disabilities. Res. Q. Exerc. Sport. 2011, 82, 239-246. [CrossRef]

21. Miesera, S.; DeVries, J.M.; Jungjohann, J.; Gebhardt, M. Correlation Between Attitudes, Concerns, Self-Efficacy and Teaching Intentions in Inclusive Education Evidence from German Pre-service Teachers using International Scales. J. Res. Spec. Educ. Needs 2019, 19, 103-114. [CrossRef]

22. Panagiotou, A.K.; Evaggelinou, C.; Doulkeridou, A.; Mouratidou, K.; Koidou, E. Attitudes of 5th and 6th Grade Greek Students Toward the Inclusion of Children with Disabilities in Physical Education Classes After a Paralympic Education Program. Eur. J. Adapt. Phys. Act. 2008, 1, 31-43. [CrossRef]

23. Alharbi, A.; Madhesh, A. Inclusive Education and Policy in Saudi Arabia. Int. J. Educ. Res. Rev. 2018, 6, 946-956.

24. Block, M.E.; Kwon, E.H.; Healy, S. Preparing Future Physical Educators for Inclusion: Changing the Physical Education Teacher Training Program. J. Braz. Soc. Adapt. Mot. Activ. 2016, 17, 9-12. [CrossRef]

25. Crawford, S.; O'Reilly, R.; Flanagan, N. Examining Current Provision, Practice and Experience of Initial Teacher Training Providers in Ireland Preparing Pre-service Teachers for the Inclusion of Students with Special Education Needs in Physical Education Classes. Eur. J. Adapt. Phys. Act. 2012, 5, 23-44. [CrossRef]

26. Morley, D.; Banks, T.; Haslingden, C.; Kirk, B.; Parkinson, S.; Van Rossum, T.; Morley, I.; Maher, A. Including Pupils with Special Educational Needs and/or Disabilities in Mainstream Secondary Physical Education: A Revisit Study. Eur. Phys. Educ. Rev. 2020, 1-18. [CrossRef]

27. Campos, M.J.; Ferreira, J.P.; Block, M.E. Exploring Teachers' Voices about Inclusion in Physical Education: A Qualitative Analysis with Young Elementary and Middle School Teachers. Compr. Psychol. 2015, 4, 10-IT. [CrossRef]

28. Haegele, J.A.; Wilson, W.J.; Zhu, X.; Bueche, J.J.; Brady, E.; Li, C. Barriers and Facilitators to Inclusion in Integrated Physical Education: Adapted Physical Educators' Perspectives. Eur. Phys. Educ. Rev. 2020, 1-15.

29. Haegele, J.A.; Zhu, X.; Davis, S. The Meaning of Physical Education and Sport among Elite Athletes with Visual Impairments. Eur. Phys. Educ. Rev. 2017, 23, 375-391. [CrossRef]

30. Hopkins, S.L.; Round, P.N.; Barley, K.D. Preparing Beginning Teachers for Inclusion: Designing and Assessing Supplementary Fieldwork Experiences. Teach. Teach. 2018, 24, 915-930. [CrossRef]

31. Pan, C.-C.; Mcnamara, S. The Impact of Adapted Physical Education on Physical Fitness of Students with Intellectual Disabilities: A Three-year Study. Int. J. Disabil. Dev. Educ. 2020, 1-16. [CrossRef]

32. Rekaa, H.; Hanisch, H.; Ytterhus, B. Inclusion in Physical Education: Teacher Attitudes and Student Experiences. A Systematic Review. Int. J. Disabil. Dev. Educ. 2019, 66, 36-55. [CrossRef]

33. Hutzler, Y.; Daniel-Shama, E. Attitudes and Self-Efficacy of Arabic-speaking Physical Education Teachers in Israel toward Including Children with Disabilities. Int. J. Soc. Sci. Stud. 2017, 5, 28-42. [CrossRef]

34. Koh, Y. A Strategy to Improve Pre-service Teachers' Self-Efficacy Towards Inclusive Physical Education for Students with Intellectual Disability and Autism. Int. J. Inclusive. Educ. 2017, 22, 839-855. [CrossRef]

35. Li, C.; Wang, L.; Block, M.E.; Sum, R.K.; Wu, Y. Psychometric Properties of the Physical Educators' Self-Efficacy Toward Including Students with Disabilities-Autism among Chinese Preservice Physical Education Teachers. Adapt. Phys. Activ. Q. 2018, 35, 159-174. [CrossRef] [PubMed]

36. Taliaferro, A.R.; Hammond, L.; Wyant, K. Preservice Physical Educators' Self-Efficacy Beliefs toward Inclusion: The Impact of Coursework and Practicum. Adapt. Phys. Act. Q. 2015, 32, 49-67. [CrossRef]

37. Block, M.E.; Hutzler, Y.; Barak, S.; Klavina, A. Creation and Validation of the Self-Efficacy Instrument for Physical Education Teacher Education Majors toward Inclusion. Adapt. Phys. Act. Q. 2013, 30, 184-205. [CrossRef] 
38. Neville, R.D.; Makopoulou, K.; Hopkins, W.G. Effect of an Inclusive Physical Education (IPE) Training Workshop on Trainee Teachers' Self-Efficacy. Res. Q. Exerc. Sport. 2019, 91, 102-114. [CrossRef]

39. Foley, J.T.; Santarossa, S.; Tindall, D.W.; Lieberman, L.J. The Impact of a Summer Sports Camp for Children with Visual Impairments on the Self-Efficacy of Physical Education Pre-service Teachers: A Pilot Study. Eur. J. Adapt. Phys. Act. 2020, 13, 3. [CrossRef]

40. Sato, T.; Haegele, J.A. Graduate Students' Practicum Experiences Instructing Students with Severe and Profound Disabilities in Physical Education. Eur. Phys. Educ. Rev. 2017, 23, 196-211. [CrossRef]

41. Li, Q.; Wang, L.; Qi, J.; Li, C. Pre-service Physical Education Techer Concerns About Teaching Students with Disabilities: Instrument Modification and Validation. Int. J. Disabil. Dev. Educ. 2020, 1-16. [CrossRef]

42. Qi, J.; Wang, L.; Ha, A. Perceptions of Hong Kong Physical Education Teachers on the Inclusion of Students with Disabilities. Asia. Pac. J. Educ. 2016, 37, 86-102. [CrossRef]

43. Jovanović, L.; Kudláček, M.; Block, M.E.; Djordjević, I. Self-Efficacy of Pre-service Physical Education Teacher toward Teaching Students with Disabilities in General Physical Education Classes in Serbia. Eur. J. Adapt. Phys. Act. 2014, 7, 32-46. [CrossRef]

44. Tindall, D.; Culhane, M.; Foley, J. Pre-service Teachers' Self-Efficacy towards Children with Disabilities: An Irish Perspective. Eur. J. Adapt. Phys. Activ. 2016, 9, 27-39. [CrossRef]

45. Layne, T.E.; Blasingame, J. Analysis of a Physical Education Teacher Education Field Experience of Working One-on-One with Students with Severe and Profound Disabilities in a Self-contained Environment. Phys. Educ. 2018, 75, 683-700.

46. Taliaferro, A.; Harris, N.P. The Effects of a One-day Workshop on Physical Educators' Self-Efficacy toward Inclusion of Students with Autism. Palaestra 2014, 28, 38-43.

47. Martin, J.J.; McCaughtry, N.; Kulinna, P.H.; Cothran, D. The Impact of a Social Cognitive Theory-based Intervention on Physical Education Teacher Self-Efficacy. Pro. Dev. Educ. 2009, 35, 511-529. [CrossRef]

48. Egido Gálvez, I.; López-Martín, E.; Manso Ayuso, J.; López, V.; Manuel, J. Determining Factors of Teachers' Self-Efficacy in Countries of the European Union: Results from TALIS 2013. Educ. XX1 2018, 21, 225-248. [CrossRef]

49. Barney, D.; Pleban, F. Pre-service Physical Education Teacher's Perceptions of Teaching Before and After a Semester Long Elementary Physical Education Practicum Experience. Phys. Educ. 2006, 63, 46-52.

50. Bandura, A. Self-Efficacy. In Encyclopedia of Human Behavior; Ramachaudran, S., Ed.; Academic Press: New York, NY, USA, 1994; Volume 4, pp. 71-81.

51. Alkhateeb, J.M.; Hadidi, M.S.; Alkhateeb, A.J. Inclusion of Children with Developmental Disabilities in Arab Countries: A Review of the Research Literature from 1990 to 2014. Res. Dev. Disabil. 2016, 49, 60-75. [CrossRef]

52. Alhumaid, M.M.; Khoo, S.; Bastos, T. Self-Efficacy of Pre-service Physical Education Teachers toward Inclusion in Saudi Arabia. Sustainability 2020, 12, 3898. [CrossRef]

53. Bandura, A. Self-Efficacy: The Exercise of Control; W.H. Freeman and Company: New York, NY, USA, 1997.

54. Bandura, A. Social Cognitive Theory of Self-regulation. Organ. Behav. Hum. Decis. Process. 1991, 50, 248-287. [CrossRef]

55. Block, M.; Taliaferro, A.; Harris, N.; Krause, J. Using Self-Efficacy Theory to Facilitate Inclusion in General Physical Education. J. Phys. Educ. Rec. Dance. 2010, 81, 43-46. [CrossRef]

56. Daniels, V.L. A Comparative Study of k12 General Education and Special Education Teachers' Self-Efficacy Levels towards Inclusion of Students with Special Needs. Ph.D. Thesis, Northcentral University, Scottsdale, AZ, USA, 2018. Available online: https: / / search.proquest.com/openview / f78add2f2c41d229cd7f26ff89901ed7 / ? pq-origsite =gscholar\&cbl=18750\&diss=y (accessed on 20 May 2020).

57. Reina, R.; Hemmelmayr, I.; Sierra-Marroquín, B. Autoeficacia de Profesores de Educación Física Para la Inclusión de Alumnos con Discapacidad y su Relación con la Formación y el Contacto Previo. Psychol. Soc. Educ. 2016, 8, 93-103. [CrossRef]

58. Reina, R.; Roldán, A.; Hemmelmayr, I.; Sierra-Marroquín, B. Incluye-T: Inclusive Physical Education and Para-Sport; CEE Limencop S.L.: Elche, Spain, 2018.

59. Nunnally, J.; Bernstein, L. Psychometric Theory, 3rd ed.; McGraw-Hill Higher, Inc.: New York, NY, USA, 1994.

60. Leech, N.L.; Barrett, K.C.; Morgan, G.A. SPSS for Intermediate Statistics: Use and Interpretation, 2nd ed.; Psychology Press: Hove, $\mathrm{UK}, 2005$.

61. Pierce, C.A.; Block, R.A.; Aguinis, H. Cautionary Note on Reporting Eta-squared Values from Multifactor ANOVA designs. Educ. Psychol. Meas. 2004, 64, 916-924. [CrossRef]

62. Nunnally, J. Psychometric Theory, 2nd ed.; McGraw-Hill Higher, Inc.: New York, NY, USA, 1978.

63. Haegele, J.A.; Hodge, S.; Filho, P.J.B.G.; de Rezende, A.L.G. Brazilian Physical Education Teachers' Attitudes toward Inclusion before and after Participation in a Professional Development Workshop. Eur. Phys. Educ. Rev. 2018, 24, 21-38. [CrossRef]

64. Hodge, S.R.; Haegele, J.; Gutierres Filho, P.; Rizzi Lopes, G. Brazilian Physical Education Teachers' Beliefs About Teaching Students with Disabilities. Int. J. Disabil. Dev. Educ. 2017, 65, 408-427. [CrossRef]

65. Maher, A.J.; Fitzgerald, H. Initial Teacher Education and Continuing Professional Development: The Perspectives of Special School Physical Education Teachers. Curr. Stud. Health Phys. Educ. 2019, 11, 18-33. [CrossRef]

66. Aldabas, R. Special Education Teachers' Perceptions of Their Preparedness to Teach Students with Severe Disabilities in Inclusive Classrooms: A Saudi Arabian Perspective. SAGE Open 2020, 10, 1-14. [CrossRef] 